responded to new historical circumstances by reorienting their relationship with the broader world. What follows are three essays from the report. The full report can be found at http://www.insidehighered.com//blogs/globalhighered/ universities-2030-learning-past-anticipate-future\#sthash. kLZri8j2.dpbs, as well as http://globalhighered.wordpress. $\mathrm{com} /$.

\section{The Research University in Brazil: I930 and 2030}

\section{Renato H. L. Pedrosa}

Renato H. L. Pedrosa is professor in the Department of Science and Technology Policy, Institute of Geosciences, University of Campinas, Brazil. E-mail: renato.pedrosa@ige.unicamp.br.

$\mathrm{B}$ razil was one of the last countries in the Americas to develop higher education. As late as I920, 400 years after the first Portuguese villages were founded in colonial Brazil, the country had not yet developed a comprehensive university. It was well behind other countries in the Americas-like Canada, the United States, and most of the former Spanish colonies-which had universities dating back to the colonial era. Brazil was not alone among former Portuguese colonies, though: Lusophone Africa, particularly Angola and Mozambique, had to wait until I962 before the first universities were established; and only after independence, in the mid-I970s, those institutions actually started to develop more fully.

The first university to be established in Brazil with a clear research mission was the University of São Paulo, in I934. In just 80 years since then, Brazil has developed a relatively large and sophisticated system of universities and other types of higher education institutions, of which about Ioo are public universities (federal and state). This system is the source of most of the research performed and graduate degrees granted in Brazil, attracting growing numbers of students-from all over the Americas, from Lusophone Africa, from Europe, and from Eastern countries such as China and South Korea. The University of São Paulo itself has the largest international student body in Brazil, with over I,300 graduate students from all over the world (20I2), most of them ( $\mathrm{I}, \mathrm{O} 42$ students) from Latin American countries, but also including groups from Angola (I6 students) and Mozambique (28 students).

\section{0}

As 1930 approached, Brazil was changing considerably, economically, and politically. Since i889, when the political system changed to a republic, power had been shared between São Paulo, due to its role as main coffee producer and its nascent industry; and Minas Gerais, a state that had been an important political player since the colonial times, due to its mining industry (gold/minerals). By the I920s, the Brazilian coffee industry had begun to decay, due to falling prices and international competition; and the financial markets' crisis of 1929 and its consequences had a very disrupting effect on a system already under severe stress. Those effects included a disruption of the democratic system, when the results of the 1930 presidential elections were contested and the losing coalition was the one that actually took power, at the end of that year.

\section{The University of SÃo Paulo is born}

Right after the change of government, new laws established the blueprint for future universities, putting forward rules that would determine the development of Brazilian higher education for the next 30 years. A new university was planned to be established in Rio de Janeiro (then the country's capital), with 328 legal articles that detailed the new institution including courses it would offer. The era of the relative decentralized development of higher education of the early republican period was over, for good. Brazil would now follow a centralized model, similar to those of France and Italy.

São Paulo, which by I932 had already led a failed revolt against the federal government, calling for a new constitution (a promise of the new rulers), took a very different approach. Júlio de Mesquita Filho-publisher of the most important newspaper in São Paulo-argued that only by becoming the country's intellectual leader would the state regain its dominance. The state's governor, Armando Oliveira, was thus convinced to start a modern research university in the state's capital.

Fernando de Azevedo, who had worked earlier on a project commissioned by Mesquita about modern universities, quickly developed a plan for the new institution, and, within weeks, the University of São Paulo was founded (January, I934). In contrast to the very detailed federal law, the new university's founding document was just 54 articles long and proposed a liberal and decentralized structure for the new institution. The first item of the second article, which established the mission of the university, is very clear: it should "promote the advancement of science by means of research." Thus, Azevedo recruited intellectuals and scientists from Europe to form the young university's faculty-among them scholars like Fernand Braudel and Claude Lévy-Strauss, who would become leaders in their 
fields after World War II. Many established scientists—such as Theodosius Dobzhansky, André Weil, and Richard Feynman-stayed for various periods in the next two decades, helping establish the new institution as the leading higher education center in the country.

The paulista enterprise has flourished. The University of São Paulo is the top university in all rankings among Latin American universities and one of the few from that continent that appears in international rankings. Brazil has developed a large group of public universities, reformed in the Ig6os with the introduction of a US-inspired graduate education model. Brazil now leads Latin American countries in research and graduate education, being 13 th in the world in the number of internationally published papers, with a share of 2.6 percent of the total world output. In I980, Brazil's share or the world's published research was just 0.2 percent, indicating how fast the system has developed in just a few decades.

\section{The new university's founding docu- ment was just 54 articles long and pro- posed a liberal and decentralized struc- ture for the new institution.}

\section{The Research University IN 2030}

Now, what would be the prospects for the research university of 2030 in Brazil? Just recently, the University of São Paulo has announced that it will start to offer massive open online courses, without any restriction regarding registration. The use of the results as credits is under debate, as it is at many universities around the world. The international trend of providing courses and even full programs, using online technology, is certainly one that the research universities will have to face; and that will likely be a very common component of most curricula very soon.

The on-campus student will still be there in 2030 , certainly. However, more and more people will develop their own program paths without having to be in residence most of the time or having to restrict themselves to a single institution. One can see graduate education expanding even more and becoming more diversified (with more programs that go beyond the traditional academic degrees-master of science/PhD), with various distinct objectives. That will go along with a less-specialized undergraduate education, another trend that will evolve from the traditional Liberal Arts/General Education curriculum, which will need to be updated and adapted to a country like Brazil but will cer- tainly have a place here and in other emergent economies. International scientific collaboration will certainly become even more common than it already is today.

Thus, despite a few gloomy predictions, the research university is well poised to remain a central actor in educational systems, its main roles being: enabling people to develop their full intellectual potential and keeping its status as the main source of innovative basic knowledge, as it has done for at least two centuries.

\section{Long Road Ahead: Moderniz- ing Chinese Universities}

\section{YANG RUI}

Yang Rui is professor at the Faculty of Education, University of Hong Kong, Pokfulam Road, Hong Kong, China. E-mail: yangrui@hku.hk.

C urrent universities are uniquely in European origin and characteristics, spreading worldwide under conditions of imperialism and colonialism as a result of the rise in Western modern human history. Thus, universities in non-Western societies have accepted underlying Western values that may not accurately reflect their own culture and traditions. For non-Western societies, indigenizing the Western model has been an arduous task in their development of modern universities.

With strikingly different cultural roots and higher learning heritages, China's attempt to integrate Chinese and Western ideas of a university is particularly illustrative. Although China is an old civilization with extraordinarily rich traditions in higher learning, modern universities are an imported concept for China. The ancient Chinese education system was established during the Yu period (22572208 BCE), and China's earliest institutions of higher learning appeared in the Western Zhou Dynasty (I046-77I $\mathrm{BCE})$. The famous Jixia Academy was established 20 years before the Platonic Academy in Greece.

\section{The Logic of the Chinese System}

Chinese higher education was evolved according to its own logic. By and large, it focused on the knowledge of human society rather than knowledge of the natural sciences. It generally disregarded knowledge about the rest of the world and confined the dissemination of knowledge to the provincial level. China's central focus was political utility, defined by the ruling classes and it thus started its higher learning 